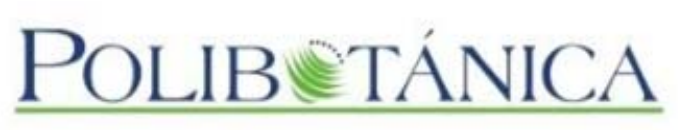

\title{
Polibotánica
}

ISSN electrónico: 2395-9525

polibotanica@gmail.com

Instituto Politécnico Nacional

México

http:www.polibotanica.mx

\section{CARACTERIZACIÓN DE LA MATA MICELIAL DE Scutellinia scutellata (L.: Fr.) Lamb.}

\section{CARACTERIZATION OF THE MICELIAL MAT OF Scutellinia scutellata (L.: Fr.) Lamb.}

\section{Loeza-Torres, E. e I. Frutis Molina.}

CARACTERIZACIÓN DE LA MATA MICELIAL DE Scutellinia scutellata (L.: Fr.) Lamb. CARACTERIZATION OF THE MICELIAL MAT OF Scutellinia scutellata (L.: Fr.) Lamb.

POLIBETANICA Instituto Politécnico Nacional
Núm. 48: 59-64 México. Julio 2019

DOI: $10.18387 /$ polibotanica.48.5

Este es un artículo de acceso abierto bajo la licencia Creative Commons 4.0 Atribución-No Comercial (CC BY-NC 4.0 Internacional). 
CARACTERIZACIÓN DE LA MATA MICELIAL DE Scutellinia scutellata (L.: Fr.) Lamb.

\section{CARACTERIZATION OF THE MICELIAL MAT OF Scutellinia scutellata (L.: Fr.) Lamb.}

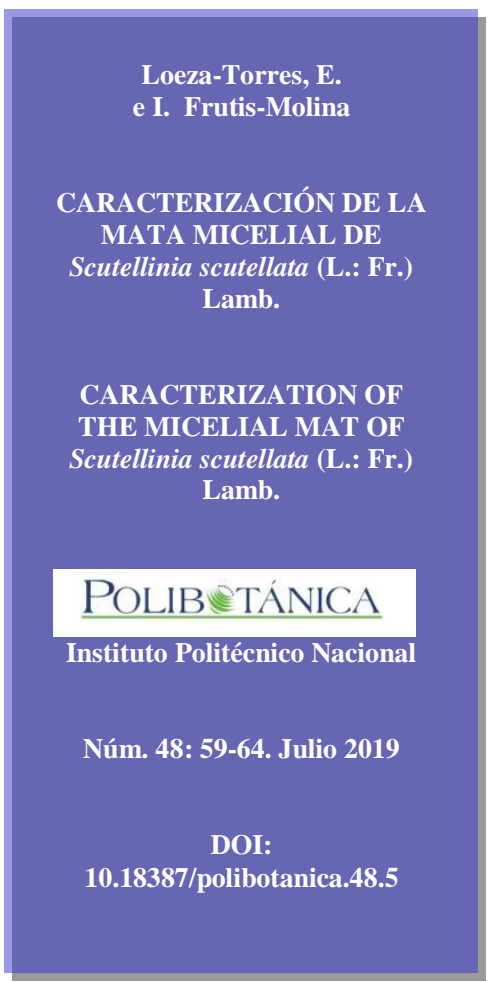

\author{
E. Loeza-Torres \\ I. Frutis-Molina \\ Herbario Facultad de Estudios Superiores Iztacala \\ Universidad Nacional Autónoma de México.
}

RESUMEN: El objetivo del presente trabajo es contribuir al conocimiento de las características del micelio a nivel de cultivo in vitro (mata miceliar) de Scutellinia scutellata empleando el sistema de (Nobles, 1965), siendo este un complemento micromorfologico para una mejor descripción. Los resultados de la aplicación de esta técnica nos muestran estructuras que no están presentes en las revisiones microscópicas de los ascocarpos así como también se pudo determinar de manera rápida y precisa el tipo de pudrición.

Palabras claves: Mata micelial, características a nivel de cultivo, Ascomycete, pudrición morena.

ABSTRACT: The objective of the present work is to contribute to the knowledge of the characteristics of the mycelium at the level of in vitro culture (mycelial mat) of Scutellinia scutellata using the system of (Nobles, 1965), this being a micromorphological complement for a better description. The results of the application of this technique show us structures that are not present in the microscopic revisions of the ascocarps as well as the type of rot could be determined quickly and accurately.

Key words: Mycelium mat, cultural characteres, Ascomycete, brown rot.

\section{INTRODUCCIÓN}

Los organismos del reino fungí presentan una gran variedad morfológica tanto macroscópica como microscopia en especial cuando nos referimos a aquellos pertenecientes a los Phylum Ascomycota y Basidiomycota. Para la determinación de un ascomiceto o un basidiomiceto es necesario considerar los caracteres morfológicos tanto los macroscópicos como los microscopios, así como también la información aportada por la microscopia electrónica y los datos moleculares, por otro lado existen un conjunto de caracteres que han tenido poca consideración y que sin embargo podrían contribuir a una caracterización más completa de los organismos: estos son los caracteres que presenta el micelio a nivel de cultivo in vitro los cuales se pueden obtener realizando un aislamiento a partir del apotecio en un medio de cultivo solido y tomando como punto de partida para su caracterización el sistema desarrollado por (Nobles, 1965), el cual fue concebido originalmente para la caracterización del micelio a nivel de cultivo in vitro y con ello la determinación de organismos del grupo de los Hymenomicetos habitantes de la madera. Por lo tanto, creemos que es un buen punto de partida para tener una caracterización más completa de aquellos organismos del Phylum Ascomycota habitantes de la madera. Considerando lo antes dicho el objetivo del presente trabajo es contribuir al conocimiento de las características del micelio a nivel de cultivo in vitro de una especie de Scutellinia encontrada sobre madera de Abies: Scutellinia scutellata. 


\section{MATERIAL Y MÉTODOS}

La especie fue colectada en el Estado de México: en la localidad de San Miguel Tecpan en el municipio de Santa Ana Jilotzingo con una vegetación de Pinus-Abies.

Una vez realizada la colecta se hizo un aislamiento de la zona del himenio y se emplearon dos medios de cultivo, el Benomyl agar (BA) el cual inhibe el crecimiento de micromicetos que pudieran estar presentes en el apotecio y agar inhibidor de bacterias (Bima) (Levy, 1976), se determinó el organismo usando las técnicas ordinarias de micología. Haciendo cortes al apotecio para la observación de ascas y ascosporas, utilizando la bibliografía especializada (Denison, 1959; Dennis, 1981; Schumacher, 1990).

Una vez obtenida la cepa de Scutellinia scutellata esta se utilizo para realizar: 1) la determinación del tipo de pudrición esta se realizo mediante la prueba de aserrín guayacol la cual consiste en agregar unas gotas de una solución alcohólica de goma de guayaco directamente al cultivo de dos semanas de crecimiento, si el tipo de pudrición es blanca el micelio tomara una coloración morada o violeta reacción positiva (+) si no se presenta cambio alguno se interpreta como una reacción negativa (-). Cómo control se utilizaron cepas de Pycnoporus sanguineus para la pudrición blanca (+) y Fomitopsis pinicola de pudrición morena como control (-) a la par de esto para reforzar los resultados obtenidos con la prueba de aserrín guayacol se empleo de método de aserrín de Badcock (Badcock, 1941; Carey, 1975; Ruiz Rodríguez, M.E.; Pinzón-Picaseño, 1995) y 2) para llevar a cabo la toma de características a nivel micro y macro morfológico del cultivo, basándose en el sistema de (Nobles, 1965). Este método consiste en colocar un inoculo de un centímetro de diámetro de la cepa pura en el extremo de una caja de Petri con un medio solido de Extracto de Malta Agar a temperatura ambiente, del crecimiento, con forma concéntrica, se tomo una muestra de tres zonas distintas con el objeto de llevar acabo revisiones microscópicas del micelio: zona madura definida como la más próxima al inoculo, zona de avance ubicada en la parte más alejada del inoculo y la zona intermedia de esta manera se revisan tres estadios de desarrollo (fig. 1).

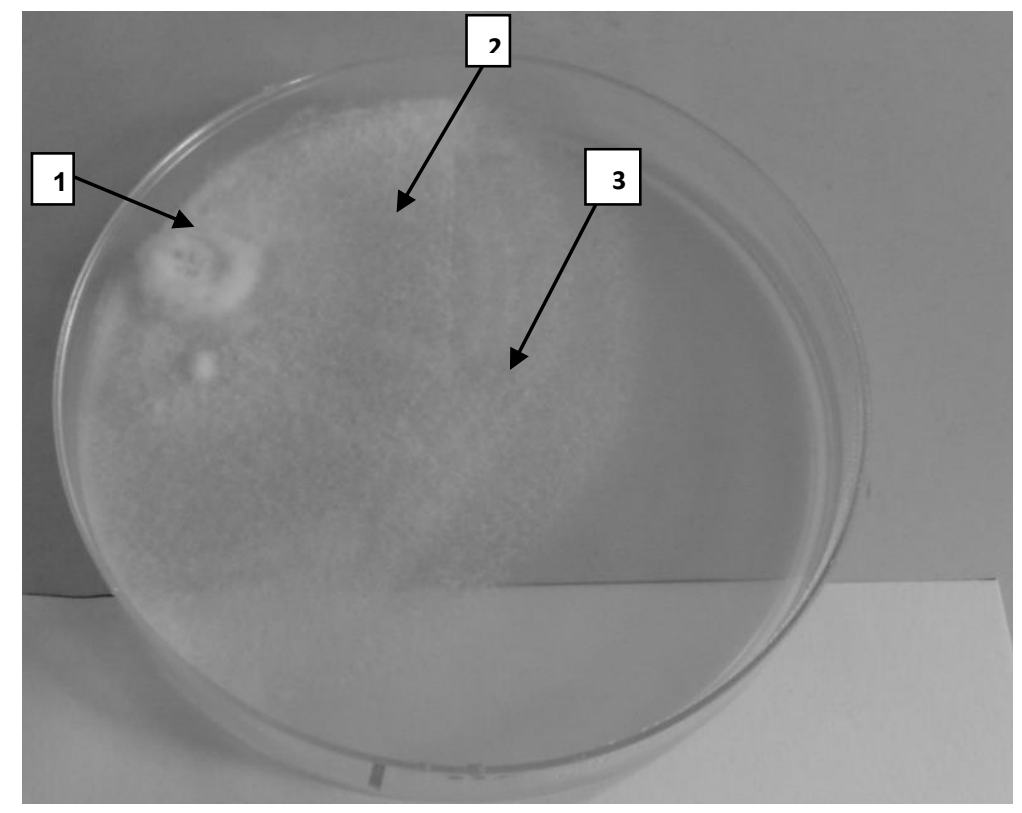

Fig. 1. Zonación generada a partir del crecimiento del inóculo de la cepa pura de Scutellinea scutellata. La zona madura (1) corresponde a la parte más vieja del inóculo, la zona intermedia corresponde a una etapa de desarrollo medio (2), la parte de la zona de avance (3) es la parte más joven del desarrollo del inóculo. 
Las revisiones se hicieron con microscopio óptico una vez por semana durante el periodo de seis semanas procurando hacerlas el mismo día de la semana. En cada una de estas se anotaron las características miceliares de cada zona, para las revisiones se utilizo el reactivo de Melzer y $\mathrm{KOH}$ al $5 \%$.

\section{Resultados}

La determinación del organismo colectado correspondió a Scutellinia scutellata (L.: Fr.) Lamb.

La descripción de las características del cultivo miceliar se presenta a continuación:

En la prueba de tipo de pudrición dio un resultado negativo lo cual nos indica que consume preferentemente celulosa y hemicelulosa característica de la pudrición morena;

Características macroscópicas:

La mata miceliar presenta un color crema, no produce cambios de color en el agar visto en la parte de abajo de la caja de petri; al medir su velocidad de crecimiento esta se cataloga como una cepa de crecimiento rápido ya que tarda semana y media (10 días) en llenar la caja de Petri; durante la duración de la prueba la cepa no presenta fructificaciones; presenta un olor frutal.

\section{Características microscópicas:}

El micelio durante las 6 revisiones presenta una combinación de hifas delgadas y gruesas con septo simple y paredes engrosadas, en ambos tipos se encontraron ramificaciones estas suelen ser cortas, a partir de la tercera semana comienzan a aparecer hifas modificadas en este caso hifas cortas en forma de " $T$ ' además de una gran cantidad de fragmentos hifales, también se observaron algunas hifas con pequeñas protuberancias, unos enrollamientos hifales suelen ser frecuentes a partir de la tercera semana de revisión (fig. 2), para la segunda semana de revisión en la zona madura aparecen algunas ascas (fig. 3), las estructuras de reproducción asexual son constantes durante todas las revisiones apareciendo estructuras como clamidosporas.

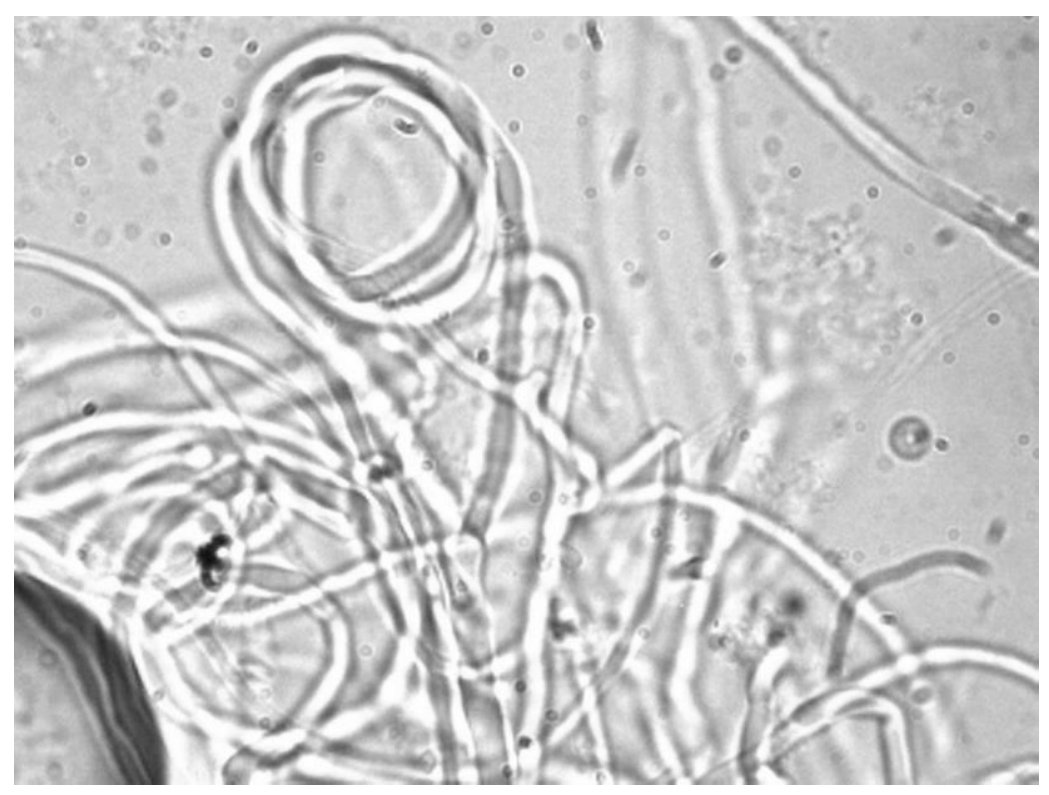

Fig. 2. Modificaciones hifales en forma de espiral de S. scutellata 100x 


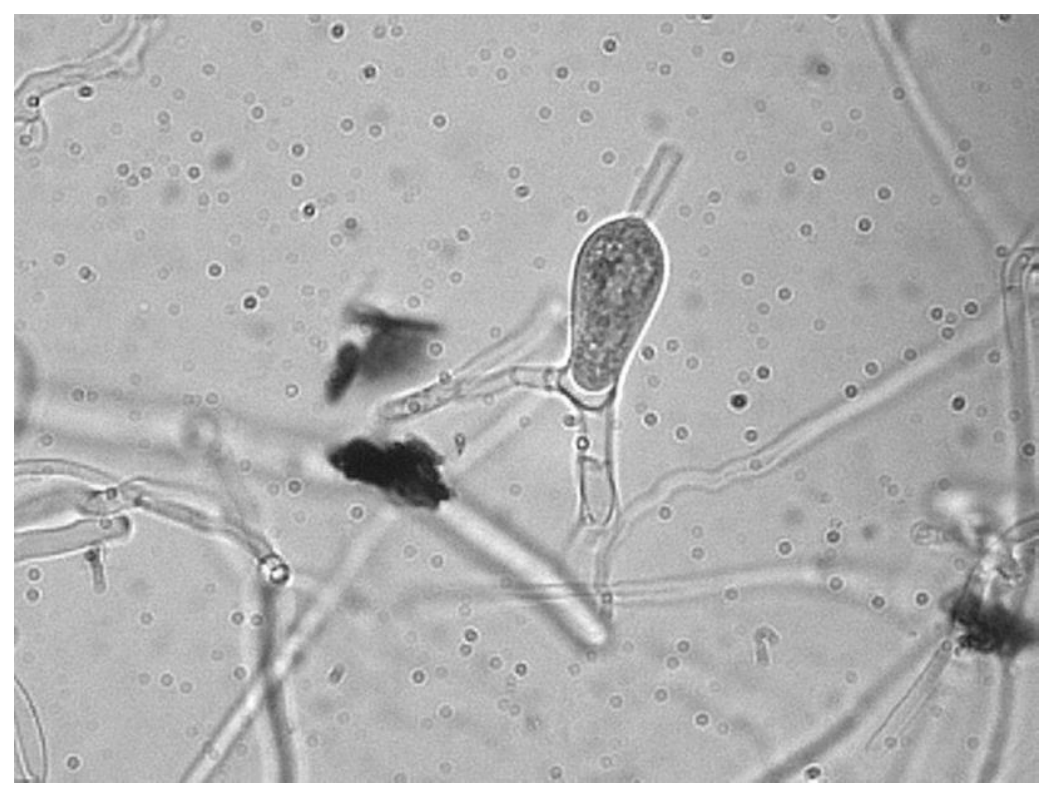

Fig. 3. Esta estructura encontrada en la zona madura del micelio en cultivo in vitro siguiendo el sistema de Nobles para Scutellinia scutellata al parecer es un asca en desarrollo.

\section{DISCUSIÓN}

Aunque el sistema de Nobles no fue desarrollado para organismos habitantes de la madera pertenecientes al Phylum Ascomycota es una buena opción tomarlo como punto de partida para realizar una caracterización más completa de estos organismos, características como el tipo de pudrición que solo habían sido determinadas mediante la prueba de aserrín-guayacol y la prueba de Badcock para Hymenomicetes, al realizarlas para un Ascomiceto como Scutellinia scutellata en este caso mostro una reacción de tipo negativo es decir que genera pudrición morena; en cuanto a los tipos hifales que podemos observar en el micelio en cultivo estos presentan particularidades propias que sin embargo guardan cierta relación con lo mencionado por el sistema de Nobles en lo referente al estadio de desarrollo en la cual aparecen. La aparición estructuras asexuales como clamidosporas que son mencionadas por Nobles y cuya aparición es también mencionada por Schumacher (1990) en su monografía para el género Scutellinia a partir de cultivos hechos por medio de la germinación de ascosporas también estuvieron presentes en este trabajo. Por otro lado, la apariencia del micelio en cultivo hacia el final de la prueba, el cual se vuelve más compacto y que está relacionado con la fructificación en el medio de cultivo de acuerdo con Nobles (1965), también fue algo que pudimos observar. Características como cambios de color en el medio de cultivo visto en la base de la caja de Petri, así como el olor mencionados en el sistema de Nobles están igualmente presentes desde las primeras revisiones

\section{CONCLUSIÓN}

Este sistema para caracterización de micelio a nivel de cultivo desarrollado por Nobles originalmente para los Hymenomicetos habitantes de la madera puede ser una herramienta útil para una caracterización más completa de ascomicetes habitantes de la madera. Como se aprecia en los resultados algunas de las estructuras encontradas en el micelio en cultivo in vitro como el micelio formando estructuras en espiral son algo nuevo, algunas otras estructuras como clamidosporas pueden también ser observadas en cultivos in vitro a partir de germinación de esporas como lo demuestra Schumacher en su monografía sobre el género Scutellinia. Una cosa 
que llama la atención es la aparición de ascas hacia la sexta semana de revisión momento en el cual el micelio presenta una apariencia compacta como es mencionado por Nobles indicando esto que el organismo empieza la producción de la fructificación. A pesar de esto hacen falta más revisiones con otros organismos tanto del mismo género como con otros ascomicetos habitantes de la madera.

\section{AGRADECIMIENTOS}

Queremos externar nuestra gratitud al módulo de Diversidad Vegetal I de la Facultad de Estudios Superiores Iztacala, así como al técnico académico biólogo Moisés Chávez Araujo y al maestro en ciencias Héctor Barrera Escoria del laboratorio de microscopia de la misma entidad por las facilidades otorgadas para la realización de este proyecto.

\section{LITERATURA CITADA}

Recibido: 18/diciembre/2018

Aceptado:

14/junio/2019
Badcock, E. C. (1941). New methods for the cultivation of wood-rotting fungi. Transactions of the British Mycological Society, 25(2), 200-IN4. https://doi.org/10.1016/s00071536(41)80008-4

Carey, J. (1975). Note on the Isolation and Characterisation of Wood-Inhabiting Fungi. Building Research Establishment Current Paper, 93(75), 11.

Denison, W. C. (1959). Some Species of the Genus Scutellinia. Mycologia, 51(5), 605-635.

Dennis, R. W. G. (1981). British Ascomycetes. Alemania: Lubrecht \& Cramer Ltd.

Levy, J. F. (1976). Isolation and identification of the fungal flora in treated wood. In Revised technique. International Research Group on Wood Preservation.

Nobles, M. K. (1965). Identification of Cultures of Wood-Inhabiting Hymenomycetes. Canadian Journal of Botany, 43(9), 1097-1139. https://doi.org/10.1139/b65-126

Ruiz Rodríguez, M.E.; Pinzón-Picaseño, L. M. (1995). Caracteres culturales de Fomitopsis pinicola y Heterobasidion annosum, hongos xilófagos de importancia forestal asociados a pudriciones en oyamel. Boletín de La Sociedad Botánica de México, 54, $225-250$.

Schumacher, T. (1990). The genus Scutellinia (Pyronemataceae). Opera Botanica, 101, 1-107. 